\title{
GUANTÁNAMO NA SUPREMA CORTE DOS ESTADOS UNIDOS ${ }^{1}$
}

\author{
Ana Luisa Zago de Moraes ${ }^{2}$
}

\begin{abstract}
RESUMO: Após os atentados de 11 de setembro de 2001, o governo norte-americano iniciou uma "guerra ao terrorismo", sendo uma das medidas o aprisionamento de supostos terroristas na Base Naval de Guantánamo, em Cuba, vedando aos detentos o acesso aos tribunais americanos e quaisquer direitos e os tratando como inimigos. Em resposta a essa situação, bem como aos atos normativos que regem o encarceramento, (não) processamento e tratamento na prisão, a Suprema Corte Americana, durante o governo de George W. Bush, proferiu três decisões nos casos de terroristas presos nestas circunstâncias. Na primeira, concluiu que o Habeas Corpus é garantia que se estende a qualquer indivíduo; na segunda, invocou o direito internacional dos direitos humanos e salientou que todos os seres humanos são titulares de algum tipo de proteção com base apenas em sua própria humanidade; por fim, na última, afastou novas normas que excluíam a garantia de Habeas Corpus e conclui que juntas militares não constituem um mecanismo justo para evitar a prisão de inocentes.
\end{abstract}

Palavras-chave: Guantánamo - Suprema Corte dos Estados Unidos - terrorismo - Direitos Humanos

\section{Guantanamo in the Supreme Court of the United States}

ABSTRACT: After the attacks of September 11, 2001, the U.S. government launched a "war on terrorism", one of the measures the imprisonment of suspected terrorists at Guantanamo Naval Base in Cuba, denying detainees access to U.S. courts and any rights and treating them as enemies. In response to this situation and the normative acts governing the incarceration, (not) processing and treatment in prison, the U.S. Supreme Court during the George W. Bush made three decisions in the cases of imprisoned terrorists in these circumstances. The first concluded that Habeas Corpus guarantees that extends to any individual; in the second, called on the international law of human rights and stressed that all humans are entitled to some kind of protection based only on his own humanity; for finally, at last, away new rules that exclude the guarantee of Habeas Corpus and concludes that military judges do not constitute a fair mechanism to prevent the arrest of innocent people.

Keywords: Guantánamo - Supreme Court of United States - terrorism - Human Rights

\section{INTRODUÇÃO}

\footnotetext{
1 Artigo elaborado em maio de 2011, no curso da disciplina de Elementos de Formação da Ordem Jurídica Internacional do Programa de Pós-Graduação em Relações Internacionais da Universidade de São Paulo (USP), sob a orientação da Prof. Dra. Deisy Ventura e do Prof. Dr. Pedro Dallari.

${ }^{2}$ Graduada em Ciências Jurídicas e Sociais pela Universidade Federal de Santa Maria (UFSM) em 2006. Mestre em Ciências Criminais pela Pontifícia Universidade Católica do Rio Grande do Sul (PUCRS) em 2008. Defensora Pública Federal em São Paulo-SP, onde atua no Grupo de Assistência a Estrangeiros. Atualmente é aluna especial do Programa de Pós-Graduação em Relações Internacionais da Universidade de São Paulo (USP). Endereço eletrônico: analuisamoraes@ hotmail.com
} 
A seleção de indivíduos, com certas características que os tornam outros em relação à sociedade - como os estrangeiros vinculados à figura do terrorista nos Estados Unidos, do terrorista e do imigrante na Europa e dos narcotraficantes na América Latina - ocorre para imputar a estes da culpa quanto à insegurança social. A esses inimigos são dirigidas leis penais mais severas e "legitimadas" por um discurso de terror, com o intuito de reduzir a sensação de insegurança que é gerada por fenômenos totalmente dissociados dos próprios inimigos aos quais se quer combater (AZEVEDO, 2006, pp. 49-57).

Nos Estados Unidos, esses inimigos são personificados nos estrangeiros vinculados à figura do terrorista, principalmente após os atentados de 11 de setembro de 2011. Em face desses inimigos, o Estado norte-americano, desde o governo de George W. Bush e mesmo durante o mandato de Barack Obama, tem imposto tratamento desumano: autoriza prisões sem acusação, tampouco processo, muito menos limitação temporal; aloca indivíduos na Base Naval de Guantánamo, fora do território nacional, de forma a assegurar a existência de um não-lugar, ou seja, um local invisível à sociedade e não tutelado pelos direitos e garantias constitucionais americanas; veda o acesso à justiça, bem como a um advogado; autoriza o uso de tortura para obter confissões, dentre outras práticas.

Cabe investigar, outrossim, qual é a resposta do Poder Judiciário norteamericano a tais violações, com base nos leading cases já apreciados pela Suprema Corte do País e, assim, aferir o papel da jurisdição interna na garantia desses direitos humanos fundamentais dos indivíduos em questão. Posteriormente, cabe introduzir o questionamento quanto à (in)efetividade desta jurisdição interna e as perspectivas desse estado de exceção que é Guantánamo ser barrado por mecanismos de tutela dos direitos nacionais e internacionais (AZEVEDO, 2006, pp. 49-57).

\section{DA SELETIVIDADE E COMBATE DE INIMIGOS NOS ESTADOS UNIDOS APÓS 11 DE SETEMBRO DE 2001}

O exemplo paradigmático de inimigo na atualidade, a partir de 11 de setembro de 2001, é o terrorista, o que evidencia a identidade do poder bélico como poder punitivo (REGHELIN, 2007, pp. 278-280 e ARANTES, 2007, pp. 147-148). Após os notórios atentados, foi promulgada, pelo presidente dos Estados Unidos, a Ordem 
Militar Presidencial estadunidense de 13 de novembro de 2001, que versa sobre a Detenção, Tratamento e Julgamento de alguns Não-Cidadãos na Guerra Contra o Terrorismo, ato normativo ao qual estão sujeitos indivíduos considerados suspeitos de integrar ou ter integrado organização terrorista, praticar, preparar ou conspirar para praticar ato terrorista, ou mesmo de hospedar terroristas. Esses indivíduos são julgados por comissões militares - diferentes dos tribunais militares previstos pelo Direito de guerra -, cuja totalidade de integrantes é diretamente nomeada pelo Secretário da Defesa, dentre oficiais integrantes das Forças Armadas (AGAMBEN, 2004, p. 14).

Com base nisso, o Secretário de Defesa, com competência legislativa, editou a Military Commission Order n. 1, de 21 de março de 2002, em que estabeleceu o procedimento a ser seguido e enunciou algumas garantias. Entretanto, as garantias são apenas formais, como o direito à defesa técnica, já que os defensores dos acusados são obrigatoriamente nomeados pelo Conselho Geral do Departamento de Defesa, dentre os oficiais das Forças Armadas que exerçam funções junto à Justiça Militar (MALAN, 2005, p. 234).

O USA Patriotic Act, promulgado pelo Senado em 26 de outubro de 2001, por sua vez, permite manter preso, sem qualquer processo legal, o estrangeiro suspeito de atividades que ponham em risco a segurança nacional dos Estados Unidos. Com isso, anulou-se radicalmente todo estatuto jurídico do indivíduo, uma vez que não são prisioneiros de guerra, tampouco acusados segundo as leis norte-americanas, ou seja, são objeto de pura dominação de fato, uma detenção indeterminada temporalmente e totalmente fora da lei e do controle judiciário (ZAFFARONI, 2007, p. 66).

O Patriotic Act viola diversas normas constitucionais norte-americanas. Exemplo disso é a possibilidade de ação da polícia sem mandado de busca e apreensão, que viola a Quarta Emenda à Constituição, que prevê a inviolabilidade de pessoas, casas, documentos e haveres, contra buscas e apreensões arbitrárias e que nenhum mandado poderá ser emitido senão com base em indícios de culpabilidade, confirmado por juramento ou declaração solene, com descrição do local e das pessoas ou coisas a serem apreendidas (DAL RI, 2006, p. 307). Daí decorre que, aplicando as normas do Patriotic Act a determinados indivíduos, estes são apontados como inimigos do povo e do Estado, sendo aniquilada sua condição de sujeitos de direito, transformando-os em seres juridicamente inomináveis e inclassificáveis (DAL RI, 2006, p. 320).

Os chamados terroristas são aprisionados na Prisão de Guantánamo, que se situa em uma base naval que recebe a mesma denominação, localizada em Cuba, 
Guantánamo, foi criada em 11 de janeiro de 2002. Para lá foram enviados os prisioneiros capturados pelas forças dos Estados Unidos que invadiram o Afeganistão logo após os atentados, assim como outros suspeitos de terrorismo, sem acusação, processo ou julgamento, e alguns dos detentos estão nessa situação desde a criação da prisão (BOUCHARD, 2004, pp. 61-72).

\section{GUANTÁNAMO NA SUPREMA CORTE DOS ESTADOS UNIDOS}

A Constituição norte-americana foi promulgada em 17 de setembro de 1787 é a mais antiga constituição escrita em vigência no mundo. Em 1791 foram ratificadas dez emendas, o Bill of Rights, ou a Declaração de Direitos. Desde 1789 mais de 10.000 emendas foram propostas e apenas 27 foram aprovadas. Dentre conteúdos relevantes do texto constitucional, para o tema em debate, destaca-se a vedação expressa de confecção de leis de exceção (bill of attainder); o direito a julgamento justo e imparcial (emenda 6); o direito potestativo à punição proporcional ao delito (emenda 8); a Suprema Corte não tem jurisdição em processo movido contra um estado por cidadão de outro estado (emenda 11); garantia de direitos civis e o implemento do due processo of Law (emenda 14) (GODOY, 2007, p. 3).

$\mathrm{Na}$ ordem jurídica estadunidense, o direito é o que o judiciário diz o que o direito seja (CELLA, 2009, p. 7). Nesse sistema, a Suprema Corte, através do judicial review, é a instância que possibilita a ação política do Poder Judiciário norte-americano, potencialmente. Através dessa prática, há a chamada definição de direitos pela Corte, que inegavelmente materializa escolhas e valores pessoais, identificando um governo de homens e não de leis.

$\mathrm{Na}$ Suprema Corte, não há direito potestativo e absoluto do cidadão norteamericano para que seja apreciada sua questão em grau de recurso, mas discricionariedade. Isso porque o processamento de recurso pela Suprema Corte decorre do deferimento de petição, o writ of certiorari, que abre caminho para complexa sustentação oral.

Com base nos leading cases, ou seja, nos casos concretos levados à Suprema Corte, o direito constitucional norte-americano transcende do texto de 1787 e se realiza nas discussões concretas que apreciam controle de constitucionalidade, poderes implícitos, supremacia de lei federal, além de questões e valores como a relação entre raças, o aborto, a liberdade religiosa, a liberdade de expressão, o controle de 
constitucionalidade de políticas públicas, a judicialização da política, a imunidade presidencial, a limitação do poder de polícia (GODOY, 2007), além dos próprios contornos do ativismo judicial ${ }^{3}$.

Em resposta à situação dos presos da Base Naval de Guantánamo, em Cuba, bem como aos atos normativos que regem o encarceramento, (não) processamento destes e seu tratamento na prisão, a Suprema Corte Americana, durante o governo de George W. Bush proferiu três decisões nos casos de terroristas presos nestas circunstâncias. Em 2010, já no período de Barack Obama, um quarto caso foi levado à Corte $^{4}$. Veja-se:

\subsection{Caso Rasul v. Bush}

Esse leading case foi argüido por dois cidadãos australianos e doze kwaitianos que foram capturados durante a missão dos Estados Unidos no Afeganistão, em

\footnotetext{
${ }^{3}$ Ativismo judicial é "uma postura a ser adotada pelo magistrado que o leve ao reconhecimento da sua atividade como elemento fundamental para o eficaz e efetivo exercício da atividade jurisdicional" (DELGADO, 2008, p. 319). Neste sentido, ainda, leciona Dworkin: "O programa do ativismo judicial sustenta que os tribunais devem aceitar a orientação das chamadas cláusulas constitucionais vagas [...]. Devem desenvolver princípios de legalidade, igualdade e assim, por diante, revê-los de tempos em tempos à luz do que parece ser a visão moral recente da Suprema Corte, e julgar os atos do Congresso, dos Estados e do presidente de acordo com isso" (DWORKIN, Ronald. in Levando os Direitos a sério, p. 215, apud DELGADO, 2008, p. 319). O ativismo judicial exige que os juízes sejam atuantes no sentido não apenas de fazer cumprir a lei em seu significado exclusivamente formal, mas exige audácia na interpretação de princípios constitucionais abstratos tais como a dignidade da pessoa humana, igualdade, liberdade, reivindicando, então, para si a competência institucional e a capacidade intelectual para fixar tais conceitos abstratos, atribuindo significado preciso aos mesmos, concretizandoos, bem como julgar os atos dos outros poderes que interpretam estes mesmos princípio (CARVALHO, 2009, p. 5).

${ }^{4}$ Esse quarto caso possui decisão de admissibilidade no site da Suprema Corte dos Estados Unidos, porém não há notícia do acórdão de julgamento do mérito, presumindo-se que ainda não tenha sido apreciado até 7 de abril de 2011. Quanto à decisão de adminissibilidade: JAMAL KIYEMBA ET AL. $v$. BARACK H. OBAMA, PRESIDENT OF THE UNITED STATES ET AL. ON WRIT OF CERTIORARI TO THE UNITED STATES COURT OFAPPEALS FOR THE DISTRICT OFCOLUMBIA CIRCUIT. No. 08-1234. Decided March 1, 2010.

Também consta a seguinte notícia recente: "NWASHINGTON, 4 Abr 2011 (AFP) -A Suprema Corte dos Estados Unidos rejeitou nesta segunda-feira três recursos apresentados por presos de Guantánamo para protestar contra sua detenção por tempo indefinido na base naval americana em Cuba. Os recursos alegam, entre outras coisas, que os direitos dos presos de questionar a prisão foram violados e que as prisões por tempo indefinio wão contrárias às leis internacionais. Um prisioneiros kuwaitiano, Fawzi al Odah, e um iemenita, Adham Mohamed Ali Awad, pedemque se questione a utilização de provas indiretas contra eles, apenas constituídas por testemunhas. Por sua parte, Ghaleb al Bihani, outro preseo iemenita, pede que se reconheça o fato de que os tratados internacioinais podem limitar o poder do presidente americano para mantê-los na prisão indefinidamente”.
} 
represália aos Talibans, no contexto de capturas de aproximadamente 680 "inimigos" e condução à Base Naval de Guantánamo, no sudoeste da costa cubana 5 .

O caso foi argüido na Corte em 20 de abril de 2004 e julgado em 28 de junho de 2004, e cuida-se de resposta dada pela Corte à questão da falta de competência dos Tribunais dos EUA para examinar a legalidade das detenções na Base Naval em liça. Anteriormente à questão ter sido levada ao Tribunal, a Court of Appeals do Estado de Columbia decidiu que não tinha jurisdição sobre a detenção de estrangeiros capturados no exterior e levados à Base Naval em comento, uma vez que se tratava de território dos Estados Unidos. Os prisioneiros alegavam, na ocasião, que não eram combatentes contra os EUA, tampouco terroristas, e que deveriam, ao menos, ter acesso aos tribunais americanos e, principalmente, a um juiz imparcial.

A Suprema Corte decidiu, nesse ponto, que a Corte Distrital tem jurisdição para julgar Habeas Corpus de pessoas em situação de custódia violadora de leis americanas, inclusive estrangeiros levados a territórios cujos Estados Unidos exercem plena e exclusiva jurisdição, a despeito de não exercer soberania definitiva (uma vez que se trata de território cubano). ${ }^{6}$

O acórdão faz uso da técnica do distinguishing, ao afastar outros precedentes de casos relacionados à sujeição de presos estrangeiros, em tempos de guerra, em locais fora dos Estados Unidos, em especial ao caso Einsentrager ${ }^{7}$. Para isso, se vale do argumento de que a Base Naval em referência equivale a uma prisão federal, de exclusivo uso dos Estados Unidos, não podendo haver distinção entre os direitos de detentos estrangeiros e cidadãos americanos, principalmente do direito de invocar a jurisdição de tribunais federais. Acrescenta, ainda, que os prisioneiros nela encarcerados

\footnotetext{
${ }^{5}$ A ocupação em questão não exclui a soberania de Cuba sobre o local, mas garante a completa jurisdição norte-americana e controle sobre a Base Naval e áreas próximas (Lease of Kands for Coaling and Naval Stations, Feb. 23, 1903, U.S - Cuba. Citado no acórdão Rasul v. Bush na parte referente à "Opinion of the Court”, p. 2).

${ }^{6}$ Leitura, síntese e tradução do acórdão n. 03-334 da Suprema Corte dos Estados Unidos, caso "RASUL et. Al. V. BUSH, PRESIDENT OF THE UNITED STATES, ET AL.". Segue a conclusão do acórdão: "Held: United States courts have jurisdiction to consider challenges to the legality of the detention of foreign nationals captured abroad connection with hostilities and incarcerated at Guantanamo Bay."

7 No caso Eisentranger a Suprema Corte sustentou que os estrangeiros presos fora dos Estados Unidos não possuem direitos constitucionais, inclusive o direito ao habeas corpus. Isso foi baseado primariamente nas implicações práticas de tal constatação, mas a Corte também traçou vários fatores que forneceram bases legais para a decisão: os peticionários são inimigos estrangeiros, que nunca residiram nos Estados Unidos, que foram capturados no estrangeiro e que foram julgados e condenados por comissões militares fora dos Estados Unidos por crimes de guerra cometidos fora de seu território, bem como foram aprisionados todas as vezes fora dos Estados Unidos.
} 
não poderão utilizar nenhuma outra jurisdição nacional, que estão há mais de dois anos presos e que não necessariamente estavam em guerra contra os Estados Unidos. ${ }^{8}$

O texto discorre, ainda, sobre a importância do instituto do Habeas Corpus na história norte-americana, para concluir sobre sua inafastabilidade. Refere que, ao longo do tempo, tem sido uma importante forma de rever detenções ilegais realizadas pelo Poder Executivo e que, por isso, é uma grande proteção aos indivíduos. Conclui que, no caso, a aplicação do instituto a pessoas detidas na Base é consistente com o alcance histórico do direito de habeas corpus. ${ }^{9}$

\subsection{Caso Hamdan v. Rumsfeld}

Trata-se do caso levado por Salid Ahmed Hamdan, cidadão iemenita capturado em 2001 no Afeganistão que, segundo o governo dos Estados Unidos, era motorista particular e guarda-costas de Osama Bin Laden. Antes de recorrer aos tribunais americanos, ficou três anos detido, sem acusação conhecida, que somente foi delimitada posteriormente como sendo crime de conspiração para a prática de atos de terrorismo, passível de julgamento por Comissão Militar. O caso foi julgado pela Suprema Corte em 29 de junho de $2006^{10}$.

Utilizando o direito de habeas corpus, reconhecido no leading case anterior, Hamdan questionou que nenhum ato do Congresso, tampouco a common Law of war poderia impor julgamento por Comissão Militar no seu caso, uma vez que se não tratava de acusação por um crime de guerra. Referiu, ainda, que os procedimentos adotados violavam o Direito internacional, inclusive o princípio de que o réu deve ter conhecimento das provas usadas contra si. A Corte distrital garantiu o direito de habeas corpus, entendendo que a autoridade do Presidente para estabelecer Comissões Militares se estende apenas aos crimes de guerra.

\footnotetext{
${ }^{8}$ O direito está previsto na "Section 2241" do Congresso norte-americano e corresponde ao direito de invocar a autoridade de cortes federais, exigindo tão-somente a existência de jurisdição de algum tribunal americano sobre a situação argüida. Concluiu a Suprema Corte que "Nothing in Eisentrager or any other of the Court's cases categorically excludes aliens detained in military custody outside the United States from that privilege. United States courts have traditionally been open to nonresident aliens")(Rasulv. Bush, Syllabus, p. 3).

${ }^{9}$ Opinion of the Court, p. 13.

${ }^{10} \mathrm{O}$ acórdão do caso HAMDAN v. RUMSFELD, SECRETARY OF DEFENSE, ET AL.
} 
Ocorre que, após a concessão do Habeas Corpus, o Congresso aprovou a s. 1005 da Lei de Tratamento ao Detento (Detainee Treatment Act), na qual o Governo alegou ter removido da jurisdição da Suprema Corte a competência para se pronunciar sobre esse pedido de habeas corpus, restringindo a competência ao Combatant Status Review Tribunals (CSRT). Essa DTA, datada de 2005, determinou que nenhum tribunal americano é competente para receber pedido de habeas corpus impetrado por estrangeiro detido na Baía de Guantánamo, tendo as Comissões Militares competência exclusiva para rever suas decisões.

$\mathrm{O}$ argumento utilizado pelo governo para a edição da DTA foi de que os tribunais federais devem se abster de interver em casos decididos por cortes marciais. Não bastasse isso, o Presidente Bush interpretou a Lei como tendo efeito retroativo e, de acordo com essa interpretação, o governo afirmou que todos os casos pendentes, incluindo o de Hamdan, deveriam ser extintos por falta de jurisdição.

Em 2006, no acórdão supramencionado, a Suprema Corte afastou o DTA de 2005, argumentando que Hamdan não é um militar e que, portanto, não é exclusiva a jurisdição das cortes marciais, invocando outros precedentes que decidem no sentido do direito de, na paz e na guerra, os Tribunais Federais preservarem garantias constitucionais e liberdades civis. Entendeu, portanto, que possuía jurisdição para julgar o pedido, afirmando que o então Presidente Bush não possuía autoridade para estabelecer comissões militares e que Hamdan teria o direito à proteção dada pelo artigo $3^{\circ}$ da Convenção de Genebra (incorporado pelo direito norte-americano) (LONTRAS, 2011). ${ }^{11}$

A Suprema Corte concluiu que os procedimentos da Comissão Militar, previstos no Millitary Commission Order No. 1, violam as quatro Convenções de Genebra, assinadas em 1949, uma vez que excluem o direito à defesa por um advogado civil, impedem os acusados de terem vista das provas apresentados, violam o direito consuetudiário que veda a produção de prova contra si mesmo, além de tramitarem de forma sigilosa, sob a alegação de segurança. Assim, presume-se a ilegalidade de qualquer decisão das Comissões Militares, não sendo justificáveis sequer sob a alegação

\footnotetext{
11 Nesse tópico, ainda, a Convenção de Genebra inaugura o que se convencionou chamar direito humanitário, em matéria internacional; isto é, o conjunto das leis e costumes da guerra, visando minorar o sofrimento de soldados doentes e feridos, bem como de populações civis atingidas por um conflito bélico. É a primeira introdução dos direitos humanos na esfera internacional. No acórdão do caso RAMDAN: "Common Article 3, by contrast, affords some minimal protection, falling short of full protectionunder the Conventions, to individuals associated with neither a signatory nor even a nonsignatory who are involved in a conflict".
} 
de que são o único mecanismo seguro em face do perigo representado pelo terrorismo internacional (Summary do acórdão do caso RAMDAN, p. 6).

Para dar provimento ao pedido de Hamdan, a Suprema Corte teve que afastar o argumento de que as Convenções de Genebra não se aplicam no caso de ter sido o preso detido no Afeganistão, que não é signatário do tratado internacional. Para isso, afirmou que, mesmo que a outra parte seja um não-signatário, deve ser garantida uma proteção mínima aos indivíduos. Foi acrescentado o fato, ainda, de que não há uma acusação clara e precisa contra Hamdan, e que a recente acusação de "conspiração" não é reconhecida no direito internacional de guerra, citando como exemplo o Tribunal Militar Internacional de Nuremberg, que se recusou a reconhecer explicitamente “conspiração para cometer crimes de guerra" como uma violação. Conclui, portanto, pela existência de mais um motivo para as Comissões Militares não terem competência para julgar o postulante (Summary do acórdão do caso RAMDAN, pp. 7-9).

Por tais razões, o caso Hamdan v Rumsfeld é reconhecido como uma reprimenda significativa para a administração Bush, no que tange a política de expansão dos poderes do Executivo em tempos de emergência, bem como uma reafirmação da Suprema Corte sobre os bem-estabelecidos limites ao Executivo frente à Constituição dos Estados Unidos. Tratou-se, portanto, de uma atitude positiva da Suprema Corte em favor dos direitos individuais durante a "Guerra contra o Terror".

Em razão disso, a solução dada para o Caso Hamdan trata-se de uma "rigthsenforcing" decision, isto é, uma decisão em que o Tribunal tenta garantir os direitos individuais, em oposição à “democracy-enforcing” decision, que corresponde a uma decisão em que o Tribunal requer que todas as leis sejam legitimadas por meio da imposição proveniente da promulgação de acordo com as regras do sistema constitucional. Ocorre que a reação do Congresso e do Executivo sobre o caso demonstrou que a decisão foi interpretada como uma maneira de forçar o Presidente a requerer autorização para criação de comissões militares e excluir Cortes Federais acerca das prisões na Baía de Guantánamo, ou seja, foi tratada como uma "democracyenforcing" decision (LONTRAS, 2011, p. 11).

Isso restou demonstrado pela $7^{\mathrm{a}}$ sessão da Lei de Comissões Militares de 2006 que substituiu a s.1005 da Lei de Tratamento dos Presos e retirou expressamente a jurisdição para receber qualquer pedido de hábeas corpus de "estrangeiro detido pelos Estados Unidos que tenha sido determinado pelo governo Norte-americano como inimigo combatente ou que aguarde essa determinação". Tal determinação foi 
expressamente dita para "aplicar a todos os casos, sem exceção, a partir da promulgação desta Lei”.

Outra questão que exsurge é que não houve uma análise constitucional da situação e dos direitos dos detentos de Guantánamo - a jurisdição foi encontrada com base na interpretação infraconstitucional, e os direitos dos presos foram direitos incorporados pela legislação doméstica, uma vez confrontada com o direito consuetudinário internacional dos direitos humanos. Assim, o caso Hamdan representou exemplo de proteção aos direitos individuais com fundamento no direito consuetudinário internacional e nos tratados internacionais (LONTRAS, 2011, p. 13).

O ponto positivo da análise do caso sob a ótica do direito internacional dos direitos humanos é a conclusão de que todo o indivíduo, em qualquer parte do mundo, dispõe de um mínimo de proteção pela ordem jurídica internacional, ou indo mais longe, "todos os seres humanos são titulares de algum tipo de proteção com base apenas em sua própria humanidade" (LONTRAS, 2011, p. 15).

\subsection{Caso Boumendiene v. Bush}

Após a $7^{\mathrm{a}}$ sessão da Lei de Comissões Militares de 2006, que retirou expressamente a jurisdição para receber qualquer pedido de hábeas corpus dos presos de Guantánamo, novo caso foi submetido a julgamento na Suprema Corte dos Estados Unidos. Cuidou-se do caso Boumedine, um dos cinco presos nascidos na Argélia que foi detido na Bósnia em outubro de 2001, sob suspeita de terem planejado um ataque contra a embaixada dos Estados Unidos. Após, foi colocado sob a custódia das tropas americanas e transportado para Guantanamo, onde foi classificado como inimigo combatente, mas nunca acusado ou julgado por qualquer crime ${ }^{12}$.

Em 12 de junho de 2008, por cinco a quatro votos, a Suprema Corte decidiu que os presos, nacionais ou estrangeiros, que forem detidos por atos de terrorismo pelo governo dos EUA poderão ter a legalidade de suas prisões contestadas em Tribunais americanos. Assim, concluiu que o Estado americano não tem poder para, sob o pretexto de combater o terrorismo, manter um nacional ou estrangeiro preso indefinidamente sem acusação formal: o declarado 'inimigo' pode ir aos Tribunais dos EUA para discutir a legalidade de sua prisão.

${ }^{12}$ LAKHDAR BOUMEDIENE ET AL. v. GEORGE W. BUSH, PRESIDENT OF THE UNITED STATES, ET AL. Acórdão 06-1195. 
Segundo Ronald Dworkin, Boumediene v. Bush é uma das mais importantes decisões da Suoprema Corte nos anos recentes, por ir de encontro à administração de Bush, que agia na forma de guerra ao terror e criou uma única categoria de prisioneiros, não cidadãos, inimigos combatentes, encarcerados em uma prisão norteamericana mas em um território estrangeiro. Essa categoria não era nem de prisioneiros de guerra, com o status legal correspondente, tampouco de prisioneiros comuns, mas de indivíduos passíveis de sofrer qualquer prática, inclusive interrogatórios mediante tortura (DWORKIN, 2008).

Assim, a Suprema Corte decidiu que esse episódio da história americana precisava terminar, e que a Constituição oferece proteção aos estrangeiros contra a própria tirania americana. Referiu expressamente que o Congresso não pode violar a Constituição que prevê que o habeas corpus somente pode ser excepcionado durante invasões e rebeliões, declarando inconstitucional a Lei de 2006. Reiterou o acórdão, por fim, que a prisão, apesar de estar em território cubano, funciona de fato como um território americano e, portanto, deve ser aplicada a Constituição. Acrescentou, novamente, que juntas militares não constituem um mecanismo justo para evitar a prisão de inocentes. ${ }^{13}$

\section{BREVES CONSIDERAÇÕES ACERCA DAS PERSPECTIVAS FUTURAS SOBRE A SITUAÇÃO DE GUANTÁNAMO}

As decisões dos três leading cases supramencionados demonstram que o constitucionalismo americano, desafiado pelo governo Bush, foi reafirmado pela Suprema Corte, que defendeu o direito de acesso aos Tribunais americanos pelos presos em Guantánamo, seja com base nas leis constitucionais, seja com fundamento no direito internacional dos direitos humanos.

Uma das promessas de Barack Obama para seu governo, que iniciou em janeiro de 2010, era o fechamento da prisão, porém, até o ano de 2011, as propostas de acabar com o encarceramento da Base Naval foram vetadas pelo Congresso Americano, e não há perspectiva de que sejam encerradas suas atividades. Pelo contrário, os ventos conduzem ao cenário de que a prisão servirá para alocação de presos vindos da Líbia e de outros locais invadidos pelos Estados Unidos.

\footnotetext{
${ }^{13}$ EUA permitem que presos de Guantánamo recorram a cortes civis. Folha de São Paulo, São Paulo, 12.06.2008. Disponível em: http://www.folha.uol.com.br/folha/cotidiano. Acesso em: 30 ago. 2008.
} 
Enquanto isso, persistem prisões com tempo indefinido em sem acusação ou processo judicial correspondente; os julgamentos pelos tribunais militares seguem ocorrendo e ainda há denúncias de tortura. Nesse sentido, foi noticiado, em agosto de 2010, que o canadense Omar Khadr, que tinha 15 anos quando foi capturado pelas forças militares no Afeganistão, em 2002, foi submetido ao primeiro julgamento em Guantánamo desde a posse de Obama, sustentando que confessou ter matado um sargento americano somente porque foi torturado durante o interrogatório ${ }^{14}$.

O que se espera é que, além do direito de acesso aos Tribunais americanos, sejam utilizados mecanismos internacionais, principalmente o direito internacional dos direitos humanos, para barrar o tratamento de indivíduos como não-cidadãos, inimigos ou meras vidas. ${ }^{15}$ Assim, seja na Base Naval de Guantánamo, seja em qualquer lugar do mundo, se almeja que, em um futuro próximo sejam abolidas as classes torturáveis e que, dentro de um pluralismo ordenado (DELMAS-MARTY, 2006, pp. 22-30) seja preservada a humanidade de todos indivíduos pelo simples fato de serem humanos.

\section{REFERÊNCIAS BIBLIOGRÁFICAS}

AGAMBEN, Giorgio. Estado de exceção. Trad. Iraci Poleti. São Paulo: Boitempo, 2004.

ARANTES, Paulo. Extinção. São Paulo: Boitempo, 2007.

AZEVEDO, Rodrigo Ghiringhelli. Visões da Sociedade Punitiva: Elementos para uma sociologia do controle penal. In: GAUER, Ruth M. C. (org.) Sistema Penal e Violência. Rio de Janeiro: Lúmen Juris, 2006.

BBC. EUA INICIAM JULGAMENTO DE ÚLTIMO OCIDENTAL EM GUANTÁNAMO. Disponível em: $<$ http://www.bbc.co.uk/portuguese/noticias/2010/08/100810_julgamento_canadense_gu antanamo_rw.shtml >. Acesso em 9 abr. 2011.

\footnotetext{
${ }^{14}$ BBC. EUA INICIAM JULGAMENTO DE ÚLTIMO OCIDENTAL EM GUANTÁNAMO.

${ }^{15}$ A expressão mera vida é utilizada por Giorgio Agamben para qualificar o indivíduo desprovido de direitos fundamentais, uma vida matável um corpo a ser docilizado por mecanismos de poder, numa clara acepção biopolítica (MARZOCCA, 2009, pp. 42-44).
} 
BOUCHARD, Marco. Guantánamo: morte do processo penal e início do apocalipse. Trad. Eduardo Maia Costa. Revista do Ministério Público. N. 97. Lisboa: 2004.

CARVALHO, Carlos Eduardo Araújo de. Ativismo judicial em crise. Jus Navigandi, Teresina, ano 14, n. 2137, 8 maio 2009. Disponível em: 〈http://jus.uol.com.br/revista/texto/12781>. Acesso em: 9 abr. 2011.

CELLA, José Renato Gazziero. Realismo Jurídico Norte-Americano e Ceticismo. Disponível em: <http://www.cella.com.br/conteudo/conteudo_28.pdf>. Acesso em: 7 abr. 2011.

DAL RI, Arno. O Estado e seus inimigos: a repressão política na história do Direito Penal. Rio de Janeiro: Revan, 2006.

DELGADO, José Augusto. Ativismo Judicial: o papel político do poder judiciário na sociedade contemporânea. In: Processo Civil Novas Tendências: homenagem ao Professor Humberto Theodoro Jr. Belo Horizonte, Del Rey, 2008.

DELMAS-MARTY, Meirelle. Les forces imaginantes du droit (II). Le Pluralisme ordonné. Paris. Seuil, 2006.

DWORKIN, Ronald. Why It Was a Great Victory. Agosto de 2008. Disponível em <http://www.nybooks.com/articles/archives/2008/aug/14/why-it-was-a-great-victory/>. Acesso em 9 abr. 2001.

ESTADOS UNIDOS DA AMÉRICA. President Issues Military Order. Detention, Treatment, and Trial of Certain Non-Citizens in the War Against Terrorism. Disponível em: <http://www.whitehouse.gov/news/releases/2001/11/20011113-27.html> Acesso em: 30 ago. 2007.

ESTADOS UNIDOS DA AMÉRICA. Military Commission Order n. 1. Procedures for Trials by Military Commissions of Certain Non-United States Citizens in the War Against Terrorism). Disponível em: <www.defenselink.mil/news/Mar2002/d20020221ord.pdf> Acesso em: 30 ago. 2007. 
EUA permitem que presos de Guantánamo recorram a cortes civis. Folha de São Paulo, São Paulo, 12.06.2008. Disponível em: <http://www.folha.uol.com.br/folha/cotidiano>. Acesso em: 30 ago. 2008.

GODOY, Arnaldo Sampaio de Moraes. Direito comparado. Introdução ao direito constitucional norte-americano. Jus Navigandi, Teresina, ano 12, n. 1515, 25 ago. 2007. Disponível em: <http://jus.uol.com.br/revista/texto/10282>. Acesso em: 7 abr. 2011.

LONTRAS, Fiona de. NA SOMBRA DO CASO HAMDAN VERSUS RUMSFELD: O DIREITO DOS PRISIONEIROS DA BAÍA DE GUANTÁNAMO AO HABEAS CORPUS. Disponível em: <http://www.panoptica.org/novfev08v2/A2_V0_N11_A13.pdf>. Acesso em 09 abr. 2011.

MALAN, Diogo Rudge. Processo penal do inimigo. Revista Brasileira de Ciências Criminais. N. 59. São Paulo, Revista dos Tribunais: 2005, p. 234.

MARZOCCA, Ottavio (Coordination). Lexique de biopolitique: lês pouvoirs sur la vie. Traduit de l'italien par Pascale Janot. Toulouse: Éditions érès: 2009.

REGHELIN, Elisangela Melo. Entre terroristas e inimigos... Revista Brasileira de Ciências Criminais. N. 66. São Paulo: Revista dos Tribunais, 2007.

ZAFFARONI, Eugenio Raúl. O inimigo no direito penal, Coleção Pensamento Criminológico $\mathrm{n}^{\circ} 14$. Rio de Janeiro: Revan, 2007. 